\title{
Etiological Study of Short Stature among Children Attending Outpatient Department of Pediatrics in a Tertiary Care Medical College Hospital
}

\author{
Imthyas Khan V. $\mathrm{H}^{1}$, Harshini B P1, Ashoka $\mathrm{C}^{2}$, Kumar G V ${ }^{3}$ \\ ${ }^{1}$ Postgraduate Student, Department of Pediatrics, Sri Siddhartha Medical College, Sri Siddhartha Academy of Higher Education, Tumkur, Karnataka, India, \\ ${ }^{2}$ Assistant professor, Department of Pediatrics, Sri Siddhartha Medical College, Sri Siddhartha Academy of Higher Education, Tumkur, Karnataka, India, \\ ${ }^{3}$ Professor, Department of Pediatrics, Sri Siddhartha Medical College, Sri Siddhartha Academy of Higher Education, Tumkur, Karnataka, India.
}

\section{Abstract}

Background: Short stature is a term applied to a child whose height is two standard deviations or more below the mean height for children of that gender and chronologic age. Familial short stature and Constitutional Growth delay are considered as normal variants, the pathological short stature includes a wide variety of underlying disorders. Chronic systemic disorders, malnutrition, chromosomal or endocrinal disorders lead to a proportionate short stature. While most of the disproportionate short stature are secondary to skeletal dysplasias or resistant rickets. Etiological evaluation plays an important role in identification of physiological as well as pathological causes of short stature. Subjects and Methods: All children of age between 2 and 18 years with height below 2 standard deviation of mean for age and gender were included in the study. Result: A total of 100 children were studied who fulfilled the criteria of short stature, out of which 61 children were male and 39 were female children. Present study showed that females had more pathological variants (72\%) than males (46\%) whereas males had more physiological variants $(54 \%)$ than females $(28 \%)$ with P-value: 0.011 Hypothyroidism was more common in females than males with $28 \%$ and $8 \%$ respectively. Genetic syndrome was more common in females than males with $10 \%$ and $3 \%$ respectively. Conclusion: Etiological evaluation is of pivotal role in identification of physiological as well as pathological causes of short stature and also helps in modifying the course of stature by means of early intervention.

Keywords: Short stature, Physiological short stature, Pathological short stature.

Corresponding Author: Dr. Kumar G V, Professor of paediatrics, Sri Siddhartha Medical College, Sri Siddhartha Academy of Higher Education, Tumkur, Karnataka, India. PIN- 572107.

Email: kumargowripura@gmail.com

Received: January 2020

Accepted: January 2020

\section{Introduction}

Growth is a continuous complex biologic process subject to genetic, environmental, nutritional and hormonal influences. Disturbance of any of these factors results in altered growth potential. $^{[1]}$ Any deviation in normal growth pattern leads to various growth disorders and can be the first sign of underlying problem. Linear growth retardation is one of them which can be detected as short stature. ${ }^{[2]}$ Short stature is a term applied to a child whose height is two standard deviations or more below the mean height for children of that gender and chronologic age (and ideally of the same racial-ethnic group). This translates into being below the third percentile for height, which is plotted against country specific growth charts. ${ }^{[3]}$ It is one of the most common problems in paediatric age group globally, especially in developing countries. ${ }^{[4]}$ Around $2.5-3 \%$ of the children worldwide are short. The evaluation of short stature starts by identifying normal variants from abnormal or pathological. While Familial short stature and Constitutional Growth delay are considered as normal variants, the pathological short stature includes a wide variety of underlying disorders. ${ }^{[5]}$

Depending on the upper-lower segment ratio pathological short stature can be further divided into proportionate and disproportionate short stature ${ }^{[6,7,8,9]}$ Chronic systemic disorders, malnutrition, chromosomal or endocrinal disorders lead to a proportionate short stature. ${ }^{[6,10,11,12]}$ While most of the disproportionate short stature are secondary to skeletal dysplasias or resistant rickets. ${ }^{[13]}$ In developing countries malnutrition and chronic systemic disorders are still the leading causes of short stature. ${ }^{[6]}$

The value of height or stature has been linked to academics, occupational placement, leadership and performance, sports participation or passage to glamour world. ${ }^{[4]}$ Psychosocial stress associated with shortness is more distressing, depending upon height deficit and child's coping skills. ${ }^{[1,4]}$

There are numerous literatures evaluating the etiological factors, effect of various community and personal level interventions to deal with weight disorders. However, there are few studies documenting the etiological profile of short stature from India. ${ }^{5}$ Etiological evaluation plays an important role in identification of physiological as well as pathological 
causes of short stature. While physiological short stature requires only parental reassurance and follows up, pathological short stature requires timely detection, evaluation and management. ${ }^{[4]}$ Hence the purpose of the study is to determine the factors causing short stature in children of age group of 2-18 years.

\section{Subjects and Methods}

This cross-sectional study was conducted in department of paediatrics in Sri Siddhartha medical college and research centre. All children of age between 2 and 18 years with height below 2 standard deviation of mean for age and gender were included in the study. Children with age less than 2 years, age more than 18 years and parents of children who are not willing to participate in the study were excluded from the study.Detailed clinical history regarding child's as well as family members was taken. Head to toe examination was done. Detailed anthropometric evaluation was done which includes: height, weight, head circumference, body mass index, mid arm circumference.Assessment of Height age, Mid parental height, Target height, Target height range was estimated. Bone age assessment is done by comparison with BA radiographs(left hand wrist joint $\mathrm{x}$ ray) of standard ages available as Greulich Pyle Atlas. The above obtained data was statistically analysed using software Epi Info software version 3.5.3.

\section{Results}

A total of 100 children were studied who fulfilled the criteria of short stature, out of which 61 children were male and 39 were female children. In the present study most of children were in the age group of $1-5 \mathrm{yrs}$, followed by $6-10$ yrs and a smaller number of children in the age group of $16-18$ yrs. Number of male and female children in the age group $1-5 \mathrm{yrs}$ were $51 \%$ and $46 \%$ respectively and less number in the age group of $16-18$ yrs with $8.2 \%$ and $5.1 \%$ respectively. [Table-1]

Table 1: Age and sex distribution among children with short stature

\begin{tabular}{|l|l|l|l|}
\hline \multirow{2}{*}{ Age Group } & \multicolumn{2}{|c|}{ Sex } & \multirow{2}{*}{ Total } \\
\cline { 2 - 3 } & \multicolumn{1}{|c|}{ Male } & \multicolumn{1}{|c|}{ Female } & \\
\hline $1-5$ & $31(50.8 \%)$ & $18(46.2 \%)$ & $49(49.0 \%)$ \\
\hline $6-10$ & $19(31.1 \%)$ & $13(33.3 \%)$ & $32(32.0 \%)$ \\
\hline $11-15$ & $6(9.8 \%)$ & $6(15.4 \%)$ & $12(12.0 \%)$ \\
\hline $16-18$ & $5(8.2 \%)$ & $2(5.1 \%)$ & $7(7.0 \%)$ \\
\hline Total & $61(100.0 \%)$ & $39(100.0 \%)$ & $100(100.0 \%)$ \\
\hline
\end{tabular}

Short stature in children were divided into pathological and physiological variants. Present study showed that females had more pathological variants $(72 \%)$ than males $(46 \%)$ whereas males had more physiological variants $(54 \%)$ than females (28\%) with P-value: 0.011 [Table-2].
Table 2: Distribution of short stature children according to pathological and physiological variants

\begin{tabular}{|l|l|l|l|}
\hline \multirow{2}{*}{ Variants } & \multicolumn{2}{c|}{ Sex } & \multirow{2}{*}{ Total } \\
\cline { 2 - 3 } & \multicolumn{1}{|c|}{ Male } & \multicolumn{1}{|c|}{ Female } & \\
\hline Pathological Variants & $28(45.90 \%)$ & $28(71.80 \%)$ & $56(56.0 \%)$ \\
\hline Physiological Variants & $33(54.10 \%)$ & $11(28.20 \%)$ & $44(44.0 \%)$ \\
\hline Total & $61(100 \%)$ & $39(100 \%)$ & $100(100.0 \%)$ \\
\hline
\end{tabular}

Chi-Square: 6.473, P-value: 0.011

Familial short stature was the most common cause of short stature. In our study familial short stature was more common in males than females with $44 \%$ and $26 \%$ respectively followed by chronic systemic disease with $20 \%$ in males and $18 \%$ in females. Hypothyroidism was more common in females than males with $28 \%$ and $8 \%$ respectively. Genetic syndrome was more common in females than males with $10 \%$ and $3 \%$ respectively. [Table-3]

Table 3: Etiology of short stature among children)

\begin{tabular}{|l|l|l|l|}
\hline \multirow{2}{*}{ Etiology } & \multicolumn{2}{c|}{ Sex } & \multirow{2}{*}{ Total } \\
\cline { 2 - 3 } & \multicolumn{1}{|c|}{ Male } & \multicolumn{1}{|c|}{ Female } & \\
\hline Familial Short Stature & $27(44.3 \%)$ & $10(25.6 \%)$ & $37(37 \%)$ \\
\hline Chronic Systemic Disease & $12(19.7 \%)$ & $8(20.5 \%)$ & $20(19 \%)$ \\
\hline Hypothyroidism & $5(8.2 \%)$ & $11(28.2 \%)$ & $16(16 \%)$ \\
\hline Malnutrition & $6(9.8 \%)$ & $3(7.7 \%)$ & $9(9 \%)$ \\
\hline Constitutional Growth Delay & $6(9.8 \%)$ & $1(2.6 \%)$ & $7(7 \%)$ \\
\hline Genetic Syndromes & $2(3.3 \%)$ & $3(7.6 \%)$ & $5(5 \%)$ \\
\hline Global Developmental Delay & $2(3.3 \%)$ & $1(2.6 \%)$ & $3(3 \%)$ \\
\hline Growth Hormone Deficiency & $1(1.6 \%)$ & $1(2.6 \%)$ & $2(2 \%)$ \\
\hline Others & $0(0 \%)$ & $1(2.6 \%)$ & $1(1 \%)$ \\
\hline Total & $61(100 \%)$ & $39(100 \%)$ & $100(100 \%)$ \\
\hline
\end{tabular}

In our study, chronic systemic disease was found in 19 children out of which 12 were males and 7 were females. Chronic bronchial asthma (26.3\%) was the most the most common cause followed by CHD-ASD (15.7\%), B thalassemia major (10.5\%), tetralogy of Fallot (10.5\%) and seizures $(10.5 \%)$. [Table 4]

Table 4: Distribution of Chronic Systemic Disease among children with short stature

\begin{tabular}{|c|c|c|c|}
\hline \multirow{2}{*}{ Chronic Systemic Disease } & \multicolumn{2}{|c|}{ Sex } & \multirow{2}{*}{ Total } \\
\hline & Male & Female & \\
\hline Chronic Bronchial Asthma & $3(25 \%)$ & $2(28.6 \%)$ & $5(26.3 \%)$ \\
\hline CHD-ASD & $3(25 \%)$ & 0 & $3(15.7 \%)$ \\
\hline B Thalassemia Major & $1(8.3 \%)$ & $1(14.3 \%)$ & $2(10.5 \%)$ \\
\hline CHD-Tetralogy of Fallot & $2(16.6)$ & 0 & $2(10.5 \%)$ \\
\hline Seizures & 0 & $2(28.6 \%)$ & $2(10.5 \%)$ \\
\hline CHD-VSD & $1(8.3 \%)$ & 0 & $1(5.2 \%)$ \\
\hline CHD- MR TR & $1(8.3 \%)$ & 0 & $1(5.2 \%)$ \\
\hline Chronic Kidney Disease & 0 & $1(14.3 \%)$ & $1(5.2 \%)$ \\
\hline Chronic liver diseases & $1(8.3 \%)$ & $1(14.3 \%)$ & $2(10.5 \%)$ \\
\hline Total & $12(100 \%)$ & $7(100 \%)$ & $19(100 \%)$ \\
\hline
\end{tabular}

\section{Discussion}

The current study exhibited male to female ratio as 1.5:1 which is similar to studies by Rabbani et al. (1.2:1), Hussain A etal (1.25:1), Manish gutch et al. (1.2:1), Moayeri etal 
(1.8:1), Bhadada et al (1.6:1)..$^{[2,15-18]}$ The studies done by Lashari et al (.9:1), Ganavi et al (.9:1), had a female predominance in short stature which is contrary to our study ${ }^{[19,20]}$ Epidemiologic data indicate that all variants of short stature are twice as common in boys as in girls. ${ }^{[20,21]}$ It is possible that this gender difference merely reflects greater parental concern about male height which leads to a selfreferral ascertainment bias. ${ }^{[17]}$ Majority of children with height falling below 3rd centile is part of normal population, with only a small number having other abnormalities. This dominance of normal variants of growth in the present study is in accordance with other worldwide studies like Moayeri et al. which was $47 \% \cdot{ }^{[22,23]}$ Utah growth study done by Lindsey etal, shows the greatest incidence of normal variant (80\%) where as other Indian studies like Bhadada et al (36.10\%), Phirke et al (26.50\%), Garg et al (24\%), Colaco et al $(29.9 \%)$ had shown similar results compared to our study. ${ }^{[23,18,15,24,25]}$

Table 5: Comparison of present study with other studies with respect to various factors of Short Stature

\begin{tabular}{|c|c|c|c|c|c|}
\hline & $\begin{array}{l}\text { Male: } \\
\text { Female }\end{array}$ & $\begin{array}{l}\text { Normal } \\
\text { Variant } \\
\mathrm{s}\end{array}$ & $\begin{array}{l}\text { Famili } \\
\text { al } \\
\text { Short } \\
\text { Stature }\end{array}$ & $\begin{array}{l}\text { Constitution } \\
\text { al Growth } \\
\text { Delay }\end{array}$ & $\begin{array}{l}\text { Pathologic } \\
\text { al causes }\end{array}$ \\
\hline $\begin{array}{l}\text { Rabbani } \\
\text { etal }^{1}\end{array}$ & $1.2: 1$ & $37.4 \%$ & $21.3 \%$ & $6.6 \%$ & $62.6 \%$ \\
\hline $\begin{array}{l}\text { LashariS K } \\
\text { etal }^{20}\end{array}$ & $0.9: 1$ & $55 \%$ & - & - & $45 \%$ \\
\hline $\begin{array}{l}\text { Lindseyetal } \\
\text { Lin }\end{array}$ & $2.7: 1$ & $80 \%$ & $37.3 \%$ & $26.8 \%$ & $20 \%$ \\
\hline $\begin{array}{l}\text { MoayaeriH } \\
\text { etal }^{17}\end{array}$ & $1.8: 1$ & $47 \%$ & $14 \%$ & $33 \%$ & $53 \%$ \\
\hline $\begin{array}{l}\text { BhaddaSk } \\
\text { etal }^{18}\end{array}$ & 1.6:1 & $36.1 \%$ & $15.09 \%$ & - & $63.9 \%$ \\
\hline 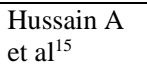 & $\begin{array}{l}1.25: \\
1\end{array}$ & $61 \%$ & $37.5 \%$ & $15.8 \%$ & $39 \%$ \\
\hline $\begin{array}{l}\text { Phirke s d } \\
\text { et } \mathrm{al}^{14}\end{array}$ & $0.7: 1$ & $26.5 \%$ & $6.1 \%$ & $20.4 \%$ & $73.5 \%$ \\
\hline $\begin{array}{l}\text { Manish } \\
\text { gutch etal. } \\
16\end{array}$ & $1.2: 1$ & $57 \%$ & $15.9 \%$ & $41.2 \%$ & $43 \%$ \\
\hline $\begin{array}{l}\text { Colaco et } \\
\mathrm{al}^{25}\end{array}$ & - & $29.9 \%$ & $20.9 \%$ & $8.4 \%$ & $70 \%$ \\
\hline $\begin{array}{l}\text { In our } \\
\text { study }\end{array}$ & $1.5: 1$ & $44 \%$ & $37 \%$ & $7 \%$ & $56 \%$ \\
\hline
\end{tabular}

Familial short stature is the single most common cause of short stature in our study which is classified under normal variant. This is in accordance with almost all worldwide studies including Lindsey et al. (37\%), Hussain A et al $(37 \%)$ and Shiva et al. (33\%). ${ }^{[23,15,26]}$ Even though familial short stature showed a greater frequency in the present study, constitutional growth delay was very less compared to other studies like Lindsey et al. (26.8\%) and Shiva et al. $(20.4 \%) \cdot{ }^{[23,26]}$ Since this study was conducted in tertiary care hospital, pathological causes accounted for $56 \%$ of total short stature. This is in accordance to study done by Rabbani et al. (62\%) and Moayeri et al. (53\%) and Bhadada et al. $(64 \%){ }^{[1,17,18]}$ In Utah study done by Lindsey et al. pathologic variants were found to be very low, ie, only $20 \%$ since it was conducted on very large population of normal school going children. ${ }^{[7]}$

The most common cause of pathological short stature was found to be chronic systemic diseases followed by hypothyroidism in our study. Chronic systemic diseases constitute $20 \%$ of the whole short stature cases, ie $36 \%$ of pathological short stature. Almost all children evaluated were having acute or chronic illness because this study was conducted in a tertiary care hospital. This may be the reason for high frequency of chronic systemic diseases. Few studies like study done by Rabbani et al. (21\%), Phirke S et al. (24\%) findings are consonant with our study, most other studies showed very less children with chronic systemic illness like Lashari S K et al. 9 (4\%), Lindsey et al. 10 (10\%), Moayeri H et al (4\%),\%), Bhadada et al. 5 (12.40\%), Ganavi et al. (10\%), Deep Dutta et al. (1.00\%) and Colaco et al. $(8.40 \%))^{[1,14,20,23,17,18,19,27,25]}$ Most of these studies are being done in endocrine clinic of tertiary hospitals where more of endocrinologic causes will be encountered. Endocrine disease was one of the causes of pathological short stature in child and it was found to be high in females than males with $31 \%$ and $10 \%$ respectively $(\mathrm{P}<0.01)$. In our study the endocrine causes for short stature was $18 \%$ whose findings are consonant with other research like Rabbani et al $(15.9 \%)$ and Phirke (12.24\%). ${ }^{[1,14]}$ Endocrine causes were low in Shiva et al. (3\%), Garg et al. (4.7\%) and high in Lashari et al. (28\%), Hussein et al. (26\%), Ganavi et al. $24 \%$ ), Colaco et al. (33.3\%) which are conflicting to our study. ${ }^{[15,19,20,24-26]}$ This may be due to the difference of study settings where each study is being done. Hypothyroidism $(16 \%)$ was the most common endocrine cause of short stature in our study. It is accordant to studies done by Bhadada et al. (14.2\%), Lashari et al. (15\%), Rabbani et al. $(17.2 \%){ }^{[1,18,20]}$ Cases of hypothyroidism was very less in Utah study done by Lindsey et al. (1\%), where mass screening of 79,495 school going children was done ${ }^{[23]}$ Growth hormone deficiency accounted for only $2 \%$ of short stature in our study.

Table 6: Comparison of present study with other studies with respect to Endocrinological causes

\begin{tabular}{|c|c|c|}
\hline & $\begin{array}{l}\text { Chronic systemic } \\
\text { disease }\end{array}$ & Endocrine causes \\
\hline Rabbani etal $^{1}$ & $21 \%$ & $15.9 \%$ \\
\hline Lashari S K etal $^{2}$ & $4 \%$ & $28 \%$ \\
\hline Lindsey etal $^{23}$ & $10 \%$ & - \\
\hline Moayaeri $\mathrm{H}$ etal $^{17}$ & $4 \%$ & - \\
\hline Bhadda $S$ etal ${ }^{18}$ & $12.4 \%$ & - \\
\hline Hussain A etal ${ }^{15}$ & - & $26 \%$ \\
\hline Ganavi ramgopal & $10 \%$ & $24 \%$ \\
\hline Phirke s d etal ${ }^{14}$ & $24.48 \%$ & $12.24 \%$ \\
\hline Deep Dutta $^{27}$ & $1 \%$ & \\
\hline Garg et $\mathrm{al}^{24}$ & $40 \%$ & $4.7 \%$ \\
\hline Colaco et $\mathrm{al}^{25}$ & $8.4 \%$ & $33.3 \%$ \\
\hline In our study & $19 \%$ & $18 \%$ \\
\hline
\end{tabular}

In our study, among pathologic short stature, malnutrition (9\%) was found to be the most common non endocrinological cause. These results were consistent with 
the worldwide studies like Utah growth study done by Lindsey et al (10\%), and various studies in India like Phirke S et al. (12.24\%), Deep Dutta et al. (6.00\%), Garg et al. $(13.00 \%)$, Colaco et al. $(8.40 \%)$, and Zarger et al. $(10.4 \%)^{[14,23-25,27,28]}$

Other causes like genetic syndrome constitute $5 \%$ of short stature which is in consonant with many Indian studies done by Bhadada et al. (7.4\%), Phirke et al. (4\%) and Deep Dutta et al. $(8 \%){ }^{[14,18,27]}$

The shortcomings of this study include failure to calculate and plot growth velocity which requires a regular follow-up at six months to twelve months interval, which was not possible in this cross-sectional study. Secondly, it was a hospital-based study where patients of specific diseases are referred.

\section{Conclusion}

Short stature is one of the most common problems in paediatric age group globally, especially in developing countries. This study helps us to know about the causes of their short stature. Physiological short stature like familial short stature requires only parental reassurance. But chronic systemic disease and hypothyroidism are preventable causes which requires timely detection, evaluation and management. Etiological evaluation is of pivotal role in identification of physiological as well as pathological causes of short stature and also helps in modifying the course of stature by means of early intervention.

\section{References}

1. Rabbani Mw, Khan Wi, Afzal Ab, Rabbani W. Causes of short stature identified in children presenting at a tertiary care hospital in multanpakistan. Pakistan journal of medical sciences. 2013 jan;29(1):53.

2. Oostdijk W, Grotefk, De Muinckkeizer-Schramasm, Witjm. Diagnostic approach in children with short stature. Hormone research in paediatrics. 2009;72(4):206-17.

3. Greulich W, Pyle SL. Radiographic atlas of skeletal development of the hand and wrist. The American Journal of the Medical Sciences. 1959 Sep 1;238(3).

4. Yadav S, Dabas A. Approach to short stature. The Indian journal of pediatrics. 2015 may 1;82(5):462-70.

5. John M, Koledova E, Kumar KMP, Chaudhari H. Review article: challenges in the diagnosis and management of Growth hormone deficiency in India. Int J Endocrinol. 2016;2016:2967578.

6. Khadilkar VV, Khadilkar AV. Practical approach to short stature. IJPP. 2011;13(4)396-401.

7. Aparna P, Parikh. An approach to short stature. Ped Clin Ind. 1995:91-9.

8. Horner JM. Growth deceleration patterns in children with constitutional short stature an aid to diagnosis. Paed. 1978;62(4):52934.

9. Chowdhury SP, Sarkar TK, Haldar D, Taraphdar P, Naskar TK, Sarkar GN. Short stature in children: experience from a tertiary care hospital in Kolkata, The Health. 2011;2(4):139-42.

10. Kamboj M. Short stature and growth hormone. The Indian Journal of Pediatrics. 2005 Feb 1;72(2):149-57.

11. Joshi RM. Genetics and congenital dwarfism. Ind $\mathrm{J}$ Ped.
1985;52:545-7.

12. Wilkins L. The diagnosis and treatment of endocrine disorders in childhood and adolescents. Southern Med J. 1951;44(5):465.

13. Srinath KS, Bhat BV, Kumar MR. Lethal forms of short limb dwarfism. Ind Pediatr. 1995;32(9):1011- 5.

14. Phirke, Deepa, Sachin O. Phirke, \& Swati Khot. "An aetiological evaluation of short stature." International Journal of Research in Medical Sciences [Online], 5.9 (2017): 3887-3890.

15. Hussein A, Farghaly H, Askar E, Metwalley K, Saad K, Zahran A, Othman HA. Etiological factors of short stature in children and adolescents: experience at a tertiary care hospital in Egypt. Therapeutic advances in endocrinology and metabolism. 2017 May;8(5):75-80.

16. Gutch M, Sukriti K, Keshav GK, Syed MR, Abhinav G, Annesh B, Mishra R. Etiology of Short Stature in Northern India. Journal of the ASEAN Federation of Endocrine Societies. 2016 May 12;31(1):23

17. Moayeri H, Aghighi Y. A prospective study of etiology of short stature in 426 short children and adolescents.

18. Bhadada SK, Agrawal NK, Singh SK, Agrawal JK. Etiological profile of short stature. The Indian Journal of Pediatrics. 2003 Jul 1;70(7):545-7.

19. Ramagopal G, Vasudevan J. Clinical and etiological profile of children with pathological short stature. International Journal of Contemporary Pediatrics. 2017 Jan;4(1):73.

20. Lashari SK, Korejo HB, Memon YM. To determine frequency of etiological factors in short statured patients presenting at an endocrine clinic of a tertiary care hospital. Pakistan journal of medical sciences. $2014 \mathrm{Jul} ; 30(4): 858$.

21. Gjikopulli A, Grimci L, Kollcaku L, Cullufi P, Tako A. Pattern and Frequency of Short Stature in Albanian Children. Current health sciences journal. 2016 Oct;42(4):390.

22. Shu SG, Chen YD, Chi CS. Clinical evaluation of short children referred by school screening: an analysis of 655 children. Acta Paediatr Taiwan. 2002;43(6):340-344.

23. Lindsay R, Feldkamp M, Harris D, Robertson J, Rallison M. Utah Growth study: growth standards and the prevalence of growth hormone Deficiency. J pediatr. 1994;125:29-35

24. Garg P. Short stature in Indian children: Experience from a community level hospital. Sri Lanka J Child Health. 2004;34:84-.

25. Colaco P, Desai M, Choksi CS. Short stature in Indian children: the extent of the problem. Indian journal of pediatrics. 1991 Sep 1;58:578.

26. Shiva S, Behbahan AG. Short stature in Iran. InHandbook of Growth and Growth Monitoring in Health and Disease 2012 (pp. 1635-1646). Springer, New York, NY.

27. Dutta D, Biswas K, Arora R, Barman N, Bhushan D, Bhakhri BK Profile and height outcomes of children with short stature in north India: an experience from a tertiary care centre. The Indian Journal of Pediatrics. 2014 Feb 1;81(2):205-6. 
Copyright: () the author(s), 2020. It is an open-access article distributed under the terms of the Creative Commons Attribution License (CC BY 4.0), which permits authors to retain ownership of the copyright for their content, and allow anyone to download, reuse, reprint, modify, distribute and/or copy the content as long as the original authors and source are cited.

How to cite this article: Khan IVH, Harshini BP, Ashoka C, Kumar GV. Etiological Study of Short Stature among Children Attending Outpatient Department of Pediatrics in a Tertiary Care Medical College Hospital. Asian J. Clin. Pediatr. Neonatol.2020;8(1):32-36.

DOI: dx.doi.org/10.47009/ajcpn.2020.8.1.8

Source of Support: Nil, Conflict of Interest: None declared. 